\title{
Ctrl+Alt+Delete: The changing landscape of the uncanny valley and the fear of second loss
}

\author{
Debra J Bassett ${ }^{1}$ (D) \\ Published online: 22 September 2018 \\ (C) The Author(s) 2018
}

\begin{abstract}
We are living in a digital era where ubiquitous social media are becoming part of the everyday lives of many. These social media platforms were designed for the living; however an estimated 8000 Facebook members die daily. It is therefore no surprise that the phenomena of how social media platforms are adopted to discuss death dying and grieving have become a growing area of research across numerous disciplines. Using qualitative methods, this article adds to and moves beyond existing research by focusing on the creation and inheritance of Facebook pages, thanablogs, posthumous chatbots, posthumous messages and posthumous avatars, to explore whether digital afterlives enabled by the Internet affect how people grieve. In order to examine how these messages and memories are experienced this study used in-depth qualitative interviews with participants from 3 distinct areas: Digital Creators (DC), Digital Inheritors (DI) and Service Providers (SP) the findings presented here explore three emerging themes (1) the link between comfort and control (2) the changing landscape of the uncanny valley and (3) the fear of 'second loss'.
\end{abstract}

Keywords Digital endurance $\cdot$ Digital immortality $\cdot$ Continuing bonds $\cdot$ Digital zombies $\cdot$ Second death $\cdot$ Second loss $\cdot$ Digital death

\section{Introduction}

Death is an undisputed reality of the human condition, and this emotionally laden topic has been researched and written about across many different disciplines. However, the Internet has spurred a relatively new and important area of research for thanatologists (those concerned with the study of death and the practises of associated with it). In 1997 Carla Sofka coined the term 'thanatechnology' to describe the bringing together of death and technology in her paper "Social support 'internetworks', caskets for sale, and more: Thanatology and the information superhighway" (Sofka 1997). Then in 2007, following the Virginia Tech shootings where 32 people died on the university campus, Facebook decided to memorialise the accounts of the dead rather than switching them off, thus enabling relatives and friends to write messages of support on the Facebook pages of the deceased. Since 2007 the Internet has fast become a digital graveyard: with Facebook profiles of

Debra J Bassett

d.j.bassett@warwick.ac.uk

1 Department of Sociology, University of Warwick, Coventry CV4 7AL, UK the deceased; memorial sites; abandoned Twitter accounts and LinkedIn profiles all contributing to a growing amount of digital data left behind by the dead. Research that emerged from these nascent phenomena has a wide academic reach, from psychology and sociology to computer human interaction and anthropology. Digital afterlife is also a key issue to a wide variety of professionals, such as grief counsellors, palliative caregivers, and educators. Existing research includes how the Internet is being used to memorialize the dead (Brubaker and Vertesi 2010; Church 2013; Marwick and Ellison 2012; Pennington 2013); mourning on social media (Brubaker et al. 2013; Cupit 2012; Walter et al. 2012); how the Internet enables continuing bonds with the dead (Bouc et al. 2016; Getty et al. 2011; Kasket 2012a; Klass et al. 1996; Refslund christensen and Sandvik 2015; Walter 2015) and grief tourism and RIP trolls (Phillips 2011).

In order to explore the nuanced and complex emotions surrounding death, dying and bereavement special consideration was given to the type of methods used: The aim of this study was to elicit rich and detailed descriptions of how messages and memories enabled by the Internet were being experienced by people in our digital society. Qualitative methods, and specifically in-depth semi-structured interviews are the most popular method to achieve this aim. In order to move 
beyond existing research into human computer interaction I interviewed participants from 3 distinct areas: Digital Creators (DC), Digital Inheritors (DI) and Service Providers (SP). My research focuses on the creation and inheritance of Facebook pages, thanablogs, posthumous chatbots, posthumous avatars and posthumous messages and in this current paper I present the findings from the DI category of participants.

\section{From Digital Immortality to Digital Endurance}

The quest for immortality has been well chronicled, from the first cave drawings and the magnificent mausoleums of the Egyptian's (Sofka 1997) to today's digital society. It can be seen as the desire to influence future generations and what Litton described as 'symbolic immortality' (Litton 1979). The term digital immortality is relatively new and is used in much - but not all - of the literature to discuss the 'posthumous persistence of digital data' (Kasket 2012a). However, just as we are biologically mortal so we are digitally mortal: loss or deletion of data and the risk of contagion is a real threat to digital immortality, as digital erasure is a possibility. Therefore, in light of this current study I suggest the term digital immortality is misleading and 'digital endurance' and 'digital afterlife' would be more useful terms when describing posthumous persistence in the field of thanatechnology.

\section{Taxonomy}

Because this area of research is relatively new, no suitable framework existed to categorise what I identified as very distinct areas: the types of participants; the types of social media platforms; and the types of messages and memories. Therefore, in order to fully explore how digital afterlives affect the bereaved I devised a taxonomy which I adopted throughout the study and which may be of use to other researchers in this area of study. Table 1 shows the abbreviations for the participant categorisation, Table 2 shows the how the service providers are categorised and Table 3 shows how the memories/messages are categorised.

It should be noted that these categories are not mutually exclusive: there are digital inheritors (DIs) who are also the creators of the digital memories (DCs), such as those who create chatbots of their dead friends or relatives, or those who create funeral films. They therefore appear in both DC and DI categories.

A limitation of this paper is that it only focuses on the findings of the digital inheritor (DI) category: those who inherit digital memories and messages following the death of a significant other. Findings from the other two categories, digital creators (DCs) and service providers (SPs), are outside the scope of this paper.

\section{Research Strategy}

Qualitative methods are suitable to illuminate how grief is experienced and can reveal how the practices, protocols and social norms of grief and bereavement may be changing in the emergent spaces created by the Internet. This research is underpinned by a social constructivist perspective, which is characterised by the assumption that reality is subjective and that phenomena and their meanings are continually being accomplished and revised by social actors (Bryman 2012). Due to the nascent nature of the research I wanted to remain open to the possibility of the generation of new theories in the field of thanatology. Initially, I was drawn to the open-minded approach to data that grounded theory offered, but it felt somewhat inflexible in its approach to reflexivity. Moreover, its assumption that data and relevant facts are 'there' to be collected-what Kelle called 'naïve empiricism (cited in Charmaz 2014)-did not take into account my epistemological position, that meaningful qualitative research should acknowledge the role and biography of the researcher, along with the agency of the participants in the co-production of knowledge. In 2000 building on the works of Glaser and Strauss and Strauss and Corbin $(1967,1990)$ Kathy Charmaz developed constructivist grounded theory: This method attempted to address what she saw as the 'objectivist' nature of traditional grounded theory, which she suggested aimed to uncover a reality independent of social actors (K Charmaz 2000). Charmaz's constructionist version of grounded theory assumes that 'social reality does not exist independent of any human action' (2000 p521). Rather she recognises that categories, concepts, and theoretical level of an analysis emerge from the researcher's interaction within the field and questions about the data (Kathy Charmaz 2014). This constructivist version of grounded theory suited my research, as it preserved the useful strategies developed by Glaser and Strauss and Strauss and Corbin, whilst integrating the more recent developments in qualitative research such as reflexivity and co-construction of data (Belgrave and Charmaz 2014). Moreover, writing in 2014 Belgrave and Charmaz (2014) suggested constructivist grounded theory can play a significant role in the field of thanatology, as it delves deeper into participants' understanding of illness, dying and death.

\section{Recruitment, Data Collection, Coding and Analysis}

Doing grounded theory research is not a linear process: crucially it is iterative. Constant comparison is a core element of grounded theory research and each part of the process influences the other. Therefore, reviewing existing literature; collecting data; coding and sorting findings; identifying themes; identifying relationships and drawing conclusions to 
Table 1 Participant

categorisation

\begin{tabular}{lll}
\hline Category & Abbreviation & Description \\
\hline Digital Creator & DC & The creators of posthumously persistent digital memories and/or messages \\
Digital Inheritor & DI & Those who inherit the digital memories and/or messages \\
Service Provider & SP & Those providing platforms for DCs and DIs \\
\hline
\end{tabular}

produce conceptual theories all happen simultaneously in this iterative methodology.

This qualitative study consisted of 31 DI participants. The social networking site Twitter was used to recruit 23 participants; Facebook to recruit 2: LinkedIn 3 and a further 3 were recruited through snowballing. In an effort to avoid 'ambulance chasing' (Cupit 2012), I wanted participants to selfselect by responding to these recruitment tweets or posts. Information sheets and consent forms were emailed to perspective participants, and once signed forms were received, semi structured interviews were conducted via Skype. Openended prompts were used to encourage the participants to discuss which media were being used, how frequently they were reading or watching the memories and messages and whether that changed over time.

I wanted to explore how digital memories and messages created and inherited from human-computer interaction enabled by the Internet were being used by the bereaved. Moreover, I wanted to understand how the memories and messages made my DIs feel, and how they would feel if they lost them. All interviews were recorded and transcribed verbatim and notes (memos) were used to record my initial thoughts while transcribing. Recruitment was on going throughout the research, and following a grounded theory approach I amended recruitment tweets and interview questions to reflect themes and patterns emerging from the transcribed interviews and memos which had been collected and coded. Table 4 below gives context to my participant's bereavement, and the memories and messages they inherited:

For the study I used NVivo, the qualitative data analysis computer software tool to store, organise and code my data. In order to elicit the participant's meanings within the data and using constructivist grounded theory as a methodological framework, within NVivo I began lineby-line coding (Kathy Charmaz 2014). Following this open-minded approach to the data, and this 'initial' process of coding, I began to amend some of the interview prompts to further investigate the emerging themes.
Memos within NVivo were used to record my interpretative notes following the interviews and during coding. Using the key strategies of constant comparative analysis and memo writing (Charmaz 2014) this simultaneous, yet iterative process of recruitment, data collection, coding and analysis, allowed me to fully investigate and clarify themes emerging from the data.

\section{Findings}

This paper presents the findings from the Digital Inheritor (DI) category. It is organised into three emergent themes. Other emergent themes, and the other two categories, digital creators (DCs) and service providers (SPs), are outside the scope of this current paper.

\section{Theme 1}

\section{The Link between Control and Comfort}

One of the core questions of this on-going research is whether digital memories and messages afforded by the Internet are affecting how people grieve. The findings of this research show the question of whether digital endurance provides comfort or disruption to bereavement, is complex and deeply entangled with the theme of control. Coding and analysis of the interviews showed that 21 of the 29 DI participants (72\%) mentioned issues of control of the data when discussing their feelings towards the digital memories or messages. Participants who feel in control of the data: that is those who have passwords or access to videos, messages, platforms and pages find comfort in the memories; whilst those who do not have passwords or access or where they are not the creator of the memories described feelings of disruption to their grief:

When my son died I didn't received any condolence cards from any of his friends ...... and then at his funeral
Table 2 Service provider categorisation

\begin{tabular}{lll}
\hline Category & Purpose & Example \\
\hline Accidental posthumous platform & Designed for the living & Facebook, Twitter \\
Intentional posthumous platform & Designed for the dead & Safebeyond, Eternime \\
\hline
\end{tabular}


Table 3 Message/memory categorisation

\begin{tabular}{ll}
\hline Category & Description \\
\hline Intentional message/memory & $\begin{array}{l}\text { Messages intentionally created to be inherited } \\
\text { Digital inheritors who message the dead as though still alive } \\
\text { (and therefore also become DCs) } \\
\text { Not intentionally created to be delivered posthumously }\end{array}$ \\
\hline
\end{tabular}

his best friend told me ..... there was a Facebook page on the Internet.... but....I can't...I don't have a Facebook account...all I have is an empty mantle....I felt left out and I don't know what to do about it .... (Cathy)

When I see the Youtube videos I hate that they are made by people who I didn't know... a part of his life I had nothing to do with.... (Grace)
I think a memorial site would work ... you know a memorial site would work for that.........because see you would ... have control..... you know it would be...the stuff on there...would be stuff to support and comfort rather than ...that dislocation ........(Grace)

Charlotte had decided to switch off her mother's Facebook page but told me she was glad it is not permanently deleted:
Table 4 Details of digital inheritor participants

\begin{tabular}{|c|c|c|c|}
\hline Pseudonym & Person Lost & Country & Memory/message inherited \\
\hline Aiden & Father & USA & Texts texts to the dead \\
\hline Ali & Friend & UK & Twitter feed; Facebook profile \\
\hline Amy & Sister & UK & Facebook profile \\
\hline Beth & Brother & USA & Audio message \\
\hline Maggie & Brother & UK & Posthumous video recording \\
\hline Cathy & Son & UK & Facebook profile \\
\hline Chloe & Father & UK & Facebook profile \\
\hline Charles & Wife & UK & Twitter feed; YouTube videos, blogs \\
\hline Dan & Friend & UK & Facebook profile \\
\hline Emma & Friend & UK & Facebook profile \\
\hline Gail & Daughter & UK & Audio message; texts to the dead \\
\hline Grace & Husband & UK & Facebook profile; YouTube videos \\
\hline Hayley & Grandfather & UK & Texts; texts to the dead \\
\hline Ivor & Daughter & UK & Facebook profile \\
\hline Jack & Father & USA & Audio message \\
\hline Jeff & Brother & UK & Funeral Video \\
\hline Jeremy & Mother & UK & Google map picture \\
\hline Jess & Son & UK & Funeral Video \\
\hline Ken & Father & UK & Texts; texts to the dead \\
\hline Kevin & Father & UK & Audio message \\
\hline Liz & Father & UK & Audio message \\
\hline Maria & Mother & USA & Audio message \\
\hline Noah & Father & USA & Chatbot \\
\hline Pam & Daughter & UK & Facebook profile; voicemail \\
\hline Riann & Brother & UK & Facebook profile; voicemail \\
\hline Sandra & Aunt & UK & LinkedIn profile; WhatsApp messages \\
\hline Sarah & Dad & USA & Texts; texts to the dead \\
\hline Sophie & Mother & Canada & Facebook profile; funeral audio \\
\hline Sharon & Husband & UK & Facebook profile \\
\hline Steve & Grandfather & UK & Texts; texts to the dead \\
\hline Vera & Father & UK & Audio message \\
\hline
\end{tabular}


I like knowing that I can switch it back on at some time in the future (Sophie)

It is important to acknowledge that grief and bereavement can be complicated, especially when families are estranged. I interviewed Chloe following the death of her estranged father, and she shared some of the direct messages between her and someone who had posted on her deceased fathers Facebook page:

Could you please delete your post on my dad's wall. Its
incredibly distressing for us. Thank you (Chloe)

When she did not get a reply she messaged again:

Are you going to leave it there or force me to tell everyone what an arsehole he was?(Chloe)

Chloe explained that she was distressed because her father had left the family when she was young. Moreover, she did not control her fathers Facebook page and other people were discussing her father's death on Facebook when she had only just found out herself. She explained:

I was really really struggling with the fact that some-

body else had announced this publicly to the

world...cause it really is to the world....

so I do think as his daughter or a wife....should be able

to control what goes on there...(Chloe)

Pam whose daughter and ex-husband had both died discussed a further example of the complexities of estranged families: Although Pam had found her daughter's Facebook profile-which she had control of -comforting she found her exhusband's Facebook page was distressing to her and her son as they did not have control of the page:

His girlfriend ......was messaging people from (....) account and that was very hurtful......for everybody .......you know you get a message from your dad when you know ...he's no longer there............ just messaged you.....what.......how spooky because she was sending messages to all sorts of people from his Facebook page and it was...very .....hurtful (Pam)

Facebook have attempted to address concerns about control and digital inheritance of profile pages with their Legacy Contact option. Legacy Contact adopts a stewardship-based approach whereby the user appoints a person to act 'for the deceased rather than as the deceased to make decisions and 'judgment calls' (Brubaker and Callison-Burch 2016). However, platforms such as Safebeyond offer timed posthumous video messages, which can be delivered on birthdays or important anniversaries of the digital inheritors. The findings of this research suggest that these timed messages may cause potential problems for the bereaved. Careful consideration should be given by platforms offering this service, to the potentially harmful affect these timed messages may have on the bereaved. Ensuring the bereaved are giving complete control, such as the option to see all timed messages at the time of inheritance, could mitigate future problems and should therefore be considered.

\section{Theme 2}

\section{The Uncanny Valley}

In 1970 the Japanese roboticist Masahiro Mori coined the term 'the uncanny valley' to describe people's reactions to robots that resemble humans too closely. He found that people liked robots that only displayed a few human characteristics, as this allowed them to fill the gaps with their imagination. However Mori noted that the more human-like the robots became, the more creepy people found them (Mori 2012). This idea was supported in 2004 with the release of the Warner Brothers films The Polar Express, a CGI animation film. Critics commented that the film made them feel creepy as the too human-like characters appeared 'soul dead' (Clinton 2004). According to Freud writing in 1917 this notion of the uncanny is linked to death and dead bodies and 'all that arouses dread and creeping horror' (Freud 2004). In the not too distant past the dead popping up on social media platforms seemed to echo this uncanny valley response.

In their 2010 study into bereavement and technology, Odom et al. describe how participants were shocked at the dead 'popping up' on social media sites (Odom et al. 2010). Other research supported this finding (Marwick and Ellison 2012; Massimi 2010; Pennington 2013). It was only in 2013 that Brubaker et al. described how the bereaved found 'new encounters with the dead' on social media platforms distressing, describing these encounters as 'startling'. In addition Walter et al. thought that the dead leaking into everyday life may be problematic (Walter et al. 2012). However, the findings of this research suggest that in the relatively short amount of time since these papers were published, people seem to be getting used to the dead popping up on the Internet. In order to fully explore this emergent theme I conducted a review of published papers where authors had mentioned the words participants used to describe feelings of unease at seeing messages on social media platforms to and from the dead. I compiled a list of words used such as 'weird' (Brubaker et al. 2013; Massimi 2012; Pennington 2013); 'gross' \& 'odd' (Brubaker et al. 2013); 'pop up' (Marwick and Ellison 2012; Odom et al. 2010); 'strange' 'shock' and 'disturbing' (Odom et al. 2010); 'creepy’ (Braman et al. 2013; 
Odom et al. 2010). I then added other words to the list (including stemmed words), which could also be used to describe feelings of unease (see Table 5 below). Selecting my DI participants I ran a text search and word frequency query from within NVivo and noted the date each interview took place. I crosschecked the findings of the query with extracts coded to the uncanny valley theme to ensure they had been used in context.

Findings showed that in the first year of this 3-year study 5 out of $9(55 \%)$ of my participants used one or more of the words on the list (in the context of the uncanny valley) this dropped to lout of $4(25 \%)$ in the second year interviews, and 0 out of $18(0 \%)$ of participants in the third year interviews. The following quotations from Grace and Pam are typical of the interviews conducted in the first year:

I mean I know that.....and its like some sort of spectral ghost .....controlling the future in a uncanny and difficult way.... (Grace)

He just messaged you..... what.......how spooky well that's not actually quite true....(Pam)

By year 3 of the study none of my participants used any of the words on the list, indicating an accretion or shallowing of the uncanny valley. However, not all human-computer communications with the dead are being normalised: Digital

Table 5 Digital Inheritors participants who used 'uncanny' words

\begin{tabular}{lllllll}
\hline & Year 1 & Year 1 & Year 1 & Year 1 & Year 1 & Year 2 \\
Digital Inheritors & Grace & Sandra & Ali & Maggie & Dan & Pam \\
\hline Uncanny & $\mathrm{X}$ & & & & & \\
Eerie & & & & & & \\
Creepy & & & & & & \\
Weird & & & & & $\mathrm{X}$ & \\
Strange & & $\mathrm{X}$ & & & & \\
Ghost & $\mathrm{X}$ & & & & \\
Spooky & & & & & \\
Odd & $\mathrm{X}$ & & & & \\
Catch you out & $\mathrm{X}$ & & & & \\
pops up & $\mathrm{X}$ & $\mathrm{X}$ & $\mathrm{X}$ & & \\
Shock & & & & $\mathrm{X}$ & \\
Unpleasant & & & & & \\
Scary & & & & \\
Horrifying & & & & \\
Alarming & & & & \\
Horrible & & & & \\
Macabre & & & & & \\
Disturbing & & & & \\
Freaky & & & & \\
Ominous & & & & \\
Gross & & & & & \\
\hline
\end{tabular}

zombies is a term used to describe the reanimated socially active dead - those who do in death things they did not do when alive (Bassett 2015). In 2013 paper Alexandra Sherlock discusses these 'posthumous representations' and how dead celebrities are being used in advertisements (Sherlock 2013): A contemporary example of this is Audrey Hepburn being used to advertise Galaxy chocolate. This dualism of being dead whilst virtually alive, and crucially socially active, can be seen in companies such as Eternime, who offer to create an avatar of you when you are alive so that you can 'give advice' to future generation after you die. These digital zombies still generate a feeling of unease and it may be what Bollmer calls the 'near full representation of the authentic identity of the human being' that people find disturbing (Bollmer 2013).

Using an illustration of Mori's uncanny valley, Fig. 1 incorporates the results of this current study to illustrate that in the 3 years since 2015 there has been a change in people's perception of the 'creepiness' of the dead 'popping up' on the Internet, resulting in a change to the landscape of Mori's uncanny valley. However, this article has obvious limitations in that it is based on one study; further research is needed to support or refute the claims suggested here.

During 2018 I interviewed Noah, a DC participant who had created a chatbot of his deceased father. Noah used the audio recordings from an oral history he had produced when his father was alive, to create his Dadbot. Interestingly, Noah's father was aware on the Dadbot before he died, and heard his wife communicating with the virtual version of himself. I asked Noah about how much he has changed or added to the Dadbot since its initial creation:

I can always add new little anecdotes for him to share, or new varieties of ways for him to express whatever he already talked about (Noah)

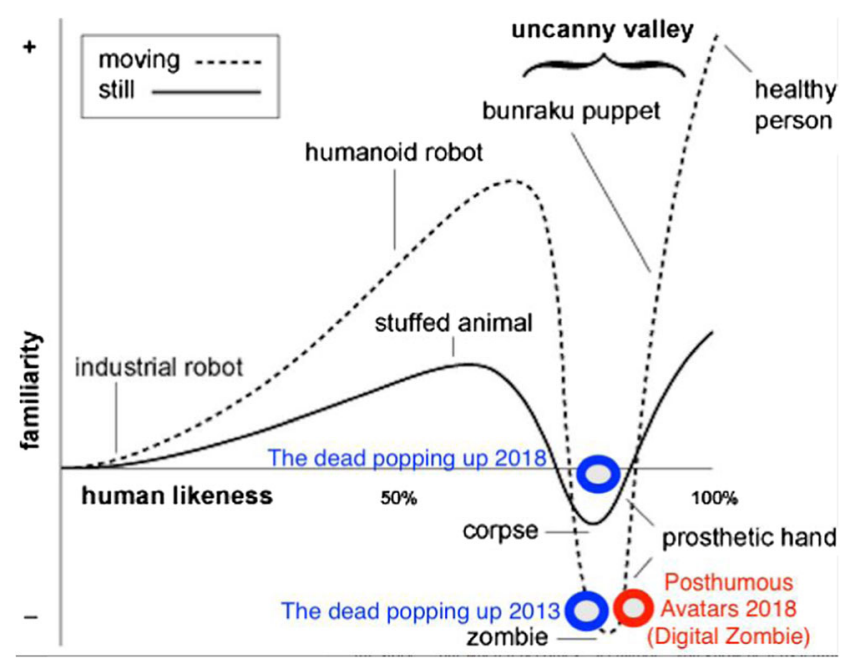

Fig. 1 Updated figure of Mori's original idea of the uncanny valley. Source: Original figure Mori IEEE Robotics \& Automation magazine 2012 
Noah explains that he can work on the listening side of the Dadbot and improve how the bot reacts to what he or someone else says to it. But crucially Noah explains why he feels there is a 'line', which he does not want to cross for fear of falling into the uncanny valley.

In the process of creating the Dadbot....I was always wanting it to be .... better and better and better.... you know with more....knowledge and.... better able to respond.... and more of my father's signature vocabulary......so I always wanted to improve it....but then at the same time there is this kind of weird .....I know there is a line....out there where....that it would somehow get...too good and then ....I would be in the uncanny valley place..... that it was creepy..... that it was becoming almost like my dad but it wasn't really him and.....I've struggled with ......been asked.....you know where is that line.....like what would,..... what if you could do him as an animation and what if you could have a synthesis of his...real voice.... and ......I knew ....I know that's a line out there and when I think about an animated version of him for instance that just gives me the creeps...personally. (Noah)

This interview with Noah was conducted in the early part of 2018, and although my findings indicate that the 'uncanny' 'creepy' vocabulary has almost disappeared from discussions around the dead popping up on social media platforms, Noah's interview suggests they could once again be used when discussing the possibility of the creation of fully animated avatars of the dead. The notion that the context in which these 'creepy' words are being used has changed, is further supported by a quotation from a DI participant from an interview conducted in 2018:

Any new messages generated by AI would seem like some sort of zombie message it would just be too creepy. (Riann)

\section{Theme 3}

\section{The Fear of Digital Death and 'Second Loss'}

Then one day I hadn't visited his page for a while, and when I searched for it, it was gone. My heart dropped. I felt panicky, I went to pictures other people had posted of him, thinking I could follow the tags to find him, but they were gone. The pictures were just his face, with no way to get to him. It was like losing him all over again, it was like a new level of loss - or, I guess, an old level of loss that the Facebook generation didn't have to deal with (Emma).

Digital endurance may blur the distinction between being alive and being dead, and could even lead to a theoretical redefining of what it means to be dead. For some, social death can predate biological death for example: the lonely or those suffering from dementia may feel isolated from society long before they die biologically. But the Internet is providing a platform where 'ordinary' people can remain socially active following biological death, which was once the realm of the rich and famous in society.

The term 'second death' was used by Patrick Stokes in his 2015 paper to discuss how the deletion of 'digital remains' may impact on the 'ontological and ethical status of the dead' (Stokes 2015). However, this current research has highlighted that digital endurance is creating a new fear for the bereaved: Fear of losing the data created by-or commemorating-the deceased. Here I build on the work of Stokes, and suggest that this second death or deletion of posthumous data is being experienced by some as a 'second loss' and the fear of this second loss is creating a new form of anxiety for the bereaved:

Last year, I had two incidents where electronic items for keepsake where lost or almost lost. Both times I had a proper meltdown and couldn't stop crying for a long time. The last incident happened in John Lewis and strangers where present. But to me they didn't exist at that time. Just my panic at losing memories and (....) all over again (Amy)

If it disappeared I would be devastated....................yep......... Its 4 years since she died.... (Sandra)

I bought some software ... because I just couldn't get the audio messages..I couldn't save them....I wanted them on my laptop......they are my most treasured thing (Amy)

I can't lose her again (Pam)

I would be devastated,.. it would start my grief all over again (Sandra)

Fear of second loss resulting from technical obsolescence of hardware, and loss of data emerges throughout the research; as Massimi and Baecker note (2010), technology is rarely designed with inheritance in mind. Pam told me how she has not upgraded her mobile phone for 5 years because of a treasured answer phone messages from her daughter, and although there are software packages available that would allow her to save the messages, she is too frightened to try them and fears that somehow she will lose some of the 'essence' of her daughter. In her 2012 paper on continuing bonds, Elaine 
Kasket reported similar findings of participant's fears at the possibility of losing Facebook profiles of the deceased (Kasket 2012b). For the bereaved, the Internet has become an important tool, which many find comforting.

\section{Future Research}

My research suggests digital erasure or 'second loss' will be an important area for future research, raising new and important questions for human-computer interaction in our digital society. However, as Meese et al. point out, the technology to create avatars of the dead draws ever closer (Meese et al. 2015) and this research has highlighted potential problems with these re-animated digital zombies. It is hoped that the service providers and designers of posthumous platforms will address issues of second loss and the creation of digital zombies in an effort to mitigate disruption to the bereaved enabled by their platforms.

This on-going research seeks to further understand how people experience this nascent phenomenon; in order to fully understand the ramifications of the inheritance of posthumous memories and messages and the effects they have on the bereaved. Social media encourages us to socialise with the living and also offers us the opportunity to ensure the dead remain part of our digital lives. For some, digital endurance is creating 'empty mantles' and isolation, however for many, digital memories and messages provide solace in dark times.

In this article I use the terms 'participants' and 'data' when describing the people who take part in my research and the precious digital memories of those they have lost. I use these terms with the utmost respect and I sincerely thank them for the time and emotional energy they have given to my study.

\section{Compliance with Ethical Standards}

Conflict of Interest The corresponding author states that there is no conflict of interest.

Ethical Approval All procedures performed in studies involving human participants were in accordance with the Ethical Guidelines of the University of Warwick, the ethical standards of the British Sociological Association, the guidelines of the Association of Internet Researchers, and with the 1964 Helsinki declaration and its later amendments.

Informed Consent Informed consent was obtained from all individual participants included in this study.

Open Access This article is distributed under the terms of the Creative Commons Attribution 4.0 International License (http:// creativecommons.org/licenses/by/4.0/), which permits unrestricted use, distribution, and reproduction in any medium, provided you give appropriate credit to the original author(s) and the source, provide a link to the Creative Commons license, and indicate if changes were made.

\section{References}

Bassett, D. (2015). Who wants to live forever? Living, dying and grieving in our digital society. Social Sciences, 4(4), 1127-1139. https://doi. org $/ 10.3390 /$ socsci4041127.

Belgrave, L., \& Charmaz, K. (2014). Studying Illness and Dying through Constructivist Grounded Theory. In L. Van Brussel \& N. Carpentier (Eds.). The Social Construction of Death: Interdisciplinary Perspectives (pp. 34-48). Springer.

Bollmer, G. D. (2013). Millions now living will never die: Cultural anxieties about the afterlife of information. The Information Society, 29(3), 142-151. https://doi.org/10.1080/01972243.2013.777297.

Bouc, A., Han, S.-H., \& Pennington, N. (2016). "Why are they commenting on his page?": Using Facebook profile pages to continue connections with the deceased. Computers in Human Behavior, 62, 635-643. https://doi.org/10.1016/j.chb.2016.04.027.

Braman, J., Vincenti, G., Dudley, A., Wang, Y., Rodgers, K., \& Thomas, U. (2013). Teaching about the impacts of social networks: An end of life perspective. Online Communities \& Social Computing (9783642393709), 240.

Brubaker, J. R., \& Callison-Burch, V. (2016). Legacy contact: Designing and implementing post-mortem stewardship at facebook. In Proceedings of the 2016 CHI Conference on Human Factors in Computing Systems (pp. 2908-2919). ACM.

Brubaker, J. R., \& Vertesi, J. (2010, April). Death and the social network. In Proc. CHI Workshop on Deaath and the Digital.

Brubaker, J. R., Hayes, G. R., \& Dourish, P. (2013). Beyond the grave: Facebook as a site for the expansion of death and mourning. The Information Society, 29(3), 152-163. https://doi.org/10.1080/ 01972243.2013 .777300 .

Bryman, A. (2012). Social reseach methods (4th ed.). Oxford: University Press.

Charmaz, K. (2000). Grounded theory: Objectivist and contructivist methods. In N. K. Denzin \& Y. Lincoln (Eds.), The handbook of qualitative research. Thousand Oaks: Sage Publications, Inc.

Charmaz, K. (2014). Constructing grounded theory. Sage.

Church, S. H. (2013). Digital Gravescapes: Digital memorializing on Facebook. The Information Society, 29(3), 184-189. https://doi. org/10.1080/01972243.2013.777309.

Clinton, P. (2004). Review: "Polar Express" a creepy ride. http://edition. cnn.com/2004/SHOWBIZ/Movies/11/10/review.polar.express/. Accessed 3 March 2018.

Cupit, I. N. (2012). In C. J. Sofka, I. N. Cupit, \& K. R. Gilbert (Eds.), Dying, death, and grief in an online universe. New York: Springer Publishing Company.

Freud, S. (2004). The uncanny. Fantastic literature: A critical reader. Westport: Praeger.

Getty, E., Cobb, J., Gabeler, M., Nelson, C., Weng, E., \& Hancock, J. T. (2011). I said your name in an empty room: grieving and continuing bonds on facebook. Proceedings of the 2011 annual conference on Human factors in computing systems (CHI '11)., 997-1000. https:// doi.org/10.1145/1978942.1979091

Glaser, B. G., \& Strauss, A. L. (1967). The discovery of grounded theory: Strategies for qualitative theory. New Brunswick: Aldine Transaction.

Kasket, E. (2012a). Being-towards-death in the digital age. Existential Analysis: Journal of the Society for Existential Analysis, 23(2).

Kasket, E. (2012b). Continuing bonds in the age of social networking: Facebook as a modern-day medium. Bereavement Care, 31(2), 6269. https://doi.org/10.1080/02682621.2012.710493.

Klass, D., Silverman, P. R., \& Nickman, S. (1996). Continuing bonds: New understandings of grief. Philadelphia: Taylor \& Francis.

Litton, R. J. (1979). The broken connection. NewYork: Simon K Schuster. 
Marwick, A., \& Ellison, N. B. (2012). “ There Isn 't Wifi in heaven !” negotiating visibility on Facebook memorial pages. Journal of Broadcasting \& Electronic Media, 56(3), 378-400.

Massimi, M. (2010). Thanatosensitively designed technologies for bereavement support. ACM.

Massimi, M., \& Baecker, R. M. (2010). A death in the family: Opportunities for designing technologies for the bereaved. In Proceedings of the SIGCHI conference on Human Factors in computing systems (pp. 1821-1830). New York: ACM.

Meese, J., Nansen, B., Kohn, T., Arnold, M., \& Gibbs, M. (2015). Posthumous personhood and the affordances of digital media. Mortality, 20(4), 408-420. https://doi.org/10.1080/13576275.2015. 1083724.

Mori, M. (2012). The uncanny valley. Trans K. F. MacDoram and N. Kageki. Robotics and Automation Magazine, 19(2), 98-100.

Odom, W., Harper, R., Sellen, A., Kirk, D., \& Banks, R. (2010). Passing on \& putting to rest. Proceedings of the 28th international conference on Human factors in computing systems - CHI '10, 1831. https://doi.org/10.1145/1753326.1753601

Pennington, N. (2013). You Don' t De-friend the dead: An analysis of grief communication by college students through Facebook profiles. Death Studies, 37(July 2015), 617-635. https://doi.org/10.1080/ 07481187.2012.673536.
Phillips, W. (2011). LOLing at tragedy: Facebook trolls, memorial pages and resistance to grief online., 16(12), 1-14.

Refslund christensen, D., \& Sandvik, K. (2015). Death ends a life not a relationship: Timework and ritualizations at mindet.Dk. New Review of Hypermedia and Multimedia, 21(1-2), 57-71. https://doi.org/10. 1080/13614568.2014.983561.

Sherlock, A. (2013). Larger than life: Digital resurrection and the reenchantment of society. The Information Society, 29(3), 164-176. https://doi.org/10.1080/01972243.2013.777302.

Sofka, C. J. (1997). Social support "internetworks." caskets for sale, and more: Thanatology and the inormation superhighway. Death Studies, 21(6), 553-574. https://doi.org/10.1080/ 074811897201778.

Stokes, P. (2015). Deletion as second death: The moral status of digital remains. Ethics and Information Technology, 17(4), 237-248. https://doi.org/10.1007/s10676-015-9379-4.

Strauss, A., \& Corbin, J. M. (1990). Basics of qualitative research: Grounded theory procedures and techniques. Sage Publications, Inc.

Walter, T. (2015). The dead who become angels: Bereavement and vernacular religion. OMEGA-Journal of Death and Dying, 73(1), 3-28.

Walter, T., Hourizi, R., Moncur, W., \& Pitsillides, S. (2012). Does the internet change how we die and mourn? Overview and analysis. OMEGA- Journal of Death and Dying, 64(4), 275-302. 